\title{
Metanalysis of Outcomes of Treatment of Mandibular Fractures
}

\author{
MOHAMED A. EL-ROUBY, M.D.; AHMED ABD EL-SALAM, M.D. and AHMED F. EL-SHERIF, M.D. \\ The Department of Plastic, Burn \& Maxillofacial Surgery, Faculty of Medicine, Ain Shams University, Cairo, Egypt
}

\begin{abstract}
Background: The exact timing of treatment of mandibular fractures remains a source of debate. Immediate repair of fractures is not always feasible; the existence of associated injuries and bad general condition might make it not practical. We performed this study to detect the difference of percentage of complications between cases of early and delayed management of mandibular fractures in order to set recommendations of the appropriate timing of work on these cases.
\end{abstract}

Methods: A retrospective study included 180 patients having isolated parasymphyseal mandibular fractures underwent chart review to document the relevant data, including the time of fracture, time of treatment and complications recorded during post-operative follow-up. Patients were categorized according to whether they had surgical intervention early post-trauma or late.

Results: $90 \%$ were males and $10 \%$ were females. Mean age of 28.74 years. $59 \%$ presented with associated zygomaticomaxillary complex fractures. Follow-up time was 6 months. No statistically significant difference in the development of post-operative complications after mandible fracture repair between the early and late treatment groups.

Conclusion: Our study has similar results to that of some of the earlier studies with addition of different variables.

Keywords: Fracture mandible-Early-Late.

\section{INTRODUCTION}

Mandibular fractures are common injuries in maxillofacial surgery [1]. In Ain Shams Plastic Surgery Department road traffic accident is the most common etiological factor causing maxillofacial trauma followed by interpersonal violence with a statistically significant higher incidence of mandibular fracture when compared to other facial fractures [2].

The development of complications involving mandibular fractures either early or late; however, is usually multi-factorial in most of cases [3]. The delay between the time of trauma and definite surgical intervention is usually implicated with the incidence of complications, however the correlation between them still yet debatable although many authors think that the delay can increase the rate of complications incidence and thus can affect the desired end result.

Our hospital is serving more than 4 million people who live in the eastern region of Cairo, and with the presence of specialized maxillofacial surgeons who adhere to the basic principles of maxillofacial fractures management; these postoperative complications could be significantly avoided. However, the lack of public hospitals specializing in this field in the surrounding region has led it to act as a secondary referral center and have increased the number of injuries likely to be referred and treated in this hospital, thus we are obliged to work on delayed cases.

Thus, in this study we aim to detect the difference of percentage of complications between cases of early and delayed management of mandibular fracture to set recommendations of the appropriate timing of work on these cases.

\section{PATIENTS AND METHODS}

This is a retrospective review of the records 180 patients with mandibular fractures operated upon in our department between January 2013 and December 2017. These patients were treated either early (Group A) or late (Group B). Early treatment is defined as treatment rendered within 72 hours (3 days) from the injury; while late treatment is defined as defined as fracture repair occurring more than 72 hours to maximum of 3 weeks the incidence of injury.

Inclusion criteria comprised the presence of a mandibular fracture treated with open reduction and internal fixation. Medical records were reviewed, and the demographic data were recorded: Age, sex, cause of the fracture, number of fractures, associated injuries, time lapse between trauma and 
definite treatment and co-morbidities. Also, we reviewed the incidence of any complication, subcategorized into infection, malocclusion, nonunion, malunion, lower eyelid ectropion, exposed plate and screws, lower lip ectropion and soft tissue dehiscence. Follow-up examinations were performed through 6 months after the injury.

The association between each type of and the time of treatment will be studied at the end of the follow-up period. Exclusion criteria for the study included patients with incomplete records and those with pan-facial fractures.

\section{Statistical analysis:}

Qualitative variables were described in terms of percent-ages, and quantitative variables in terms of means, standard deviations and medians. Variables were compared and analyzed between the 2 groups using Fisher's exact test and Pearson's chi-squared test for categorical variables and Student's two-sample $t$-test and the Wilcoxon two sample test for continuous variables. The results with $p$ less than 0.05 were considered statistically significant.

\section{RESULTS}

In this study, there were 180 cases of mandibular fractures surgically treated in the period of 5 years. Of these patients, 48 patients were treated early and 132 were treated late. $30 \%$ presented with single fracture while the rest had multiple fractures, while 59\% had associated zygomaticommaxillary fractures. The average age was $25.7 \pm 3.1$ years old, with the youngest age was 9 years old and the oldest was 52 years old. Of this population, $90 \%$ were males and $10 \%$ were females (Table 1 ).

Table (1): Patients' data.

\begin{tabular}{lll}
\hline & $\begin{array}{c}\text { Group A } \\
\text { (Early) }\end{array}$ & $\begin{array}{c}\text { Group B } \\
\text { (Late) }\end{array}$ \\
\hline Number of patients & 48 & 132 \\
Mean age & 24.8 & 26.2 \\
Male: Female & $9: 1$ & $9: 1$ \\
\hline
\end{tabular}

The main causes of these fractures were motor car accidents (44\%) followed by violence $(35 \%)$, occupational injuries (11\%), fall from height (8\%) and sports accidents (2\%) Fig. (1).

The condyle area was the most common site in $42 \%$ of cases. $31 \%$ symphyseal and parasymphyseal fractures, $20 \%$ angle fractures and $7 \%$ fractures of ramus were noted Fig. (2).

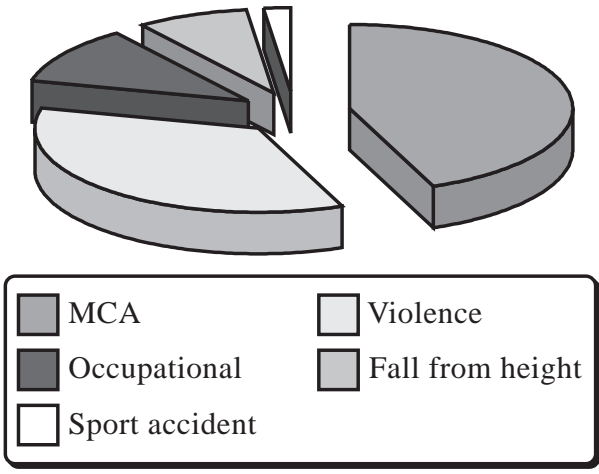

Fig. (1): Aetiology of the fracture in all included patients.
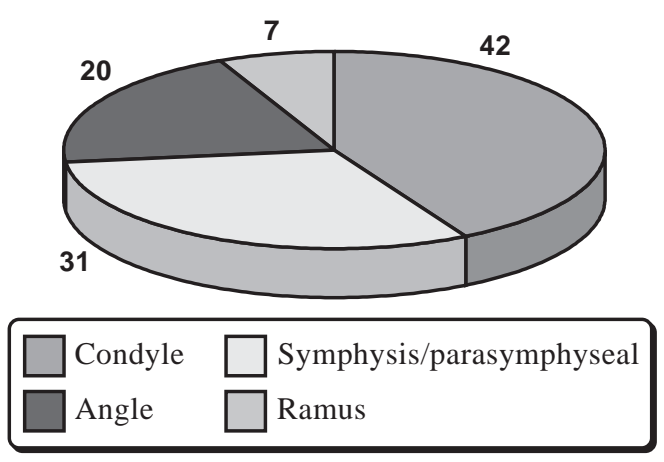

Fig. (2): Percentage of site of fracture mandible.

Mean time to repair for the early group was 2 days (range one to three days) versus 17.8 days (range 5 to 21 days) for the delayed group. All patients in both groups underwent open reduction and internal fixation. The average hospital stay for the early group was 5 days, while in the late group it was 15 days.

Complications were evaluated after 6 months and we recorded a total of 49 complications. These included 9 infections, 15 malocclusions, 5 nonunion cases, 13 malunion cases, 4 cases of soft tissue dehiscence, 1 case of lower lip ectropion and 2 cases of plate and screw exposure. In Group A, rate of complications was 26\% (13 patients) while in Group B, it was 27\% (36 patients) (Table 2).

Table (2): Complication incidence of both groups ( $p$-value $<0.05$ is statistically significant).

\begin{tabular}{llll}
\hline & $\begin{array}{c}\text { Group A } \\
\text { (Early) }\end{array}$ & $\begin{array}{c}\text { Group B } \\
\text { (Late) }\end{array}$ & $\begin{array}{c}p- \\
\text { value }\end{array}$ \\
\hline Infection & $2(4 \%)$ & $7(5 \%)$ & 0.871 \\
Malunion & $3(6 \%)$ & $10(8 \%)$ & 0.142 \\
Nonunion & $2(4 \%)$ & $3(2 \%)$ & 0.613 \\
Malocclusion & $3(6 \%)$ & $12(9 \%)$ & 0.251 \\
Lower lip ectropion & $1(2 \%)$ & - & - \\
Plate and screw exposure & - & $2(1.5 \%)$ & - \\
Soft tissue dehiscence & $2(4 \%)$ & $2(1.5 \%)$ & 0.375 \\
\hline Total & $13(26 \%)$ & $36(27 \%)$ & 0.962 \\
\hline
\end{tabular}




\section{DISCUSSION}

Occurrence of complications following mandibular fractures is a problem that arises as a result of an initial condition or as an outcome of treatment. Accurate diagnosis and appropriate treatment plan are vital in decreasing complications. However, even when all proper surgical principles are strictly followed, a percentage of mandibular fractures may develop improper sequelae [4].

The role of treatment timing on the outcome of mandibular fractures has been the subject of extensive debate for many years; early surgical interventions prior to osseous callus formation and soft tissue fibrosis has been advocated by most of the authors aiming to achieve the best functional outcome [5,6].

Early treatment, within the first few hours after trauma, is said to be associated with fewer rates of post-operative infections, while delayed treatment (1-2 weeks after trauma) is believed to be accompanied with increased risk of infection [7]. Malanchuk and Kopchak [8] in a study of 334 patients reported a significant association between delayed treatment (more than 7 days) and the development of infection. Webb et al., [9] in a retrospective study of 33 patients with mandibular fractures found that delaying treatment for more than 72 hours does not significantly increase the risk of infection.

Anderson and Alpert [10] displayed a 16\% overall post-operative infection rate in a study of 75 mandible fractures, but no infections occurred in patients operated on within 24h of injury. In 1997 Khoury [11], found that patients presenting 6 or more days after injury have a high pre-operative rate of infection.

Despite these many studies that show a correlation between earlier treatment and decreased morbidity, others have believed that a lag time to repair is needed to allow for a decrease in edema in the surrounding soft tissues and showed that this delay didn't increase the rate of complications $[6,12,13]$.

Barker et al., in 2011 [14], performed a chart review on 83 patients with mandible fractures over a 5 year period at a single institution; the mean time from injury to fixation was 6.7 days and no correlation was found between increased time to repair and the rate of complications (infection, nonunion, or malunion). A trend was found between fewer complications and increasing time to surgical repair.
Recently a systematic review on 30 studies was done to examine the effects of treatment delay on outcome in the management of facial fractures. Eighteen studies found no statistically significant relationship between treatment delay and treatment outcome. Nine studies found a statistically significant relationship between treatment delay and worse treatment outcomes. There were three studies with conflicting results and authors concluded that definitive conclusions cannot be drawn on the timing of treatment for facial fractures [15].

In the present study we reviewed the medical records of patients who had surgical intervention to fracture mandible to assess the impact of the timing of intervention on the rate of complications. We usually advocate early open reduction and internal fixation for mandibular fractures. However, this is not always the rule as we are frequently forced to perform a late surgical interference due to many reasons as neurological or surgical instability, associated co-morbidities or late presentation of patients. Our study did not reveal a statistically significant difference in the development of a postoperative complication after mandibular fractures repair between the early and late treatment groups.

In addition to this debate on the timing of repair, the definition of a fixed timing that delineate early from late was always variable and undefined and most of the studies described the term "delayed treatment" in varying durations. Champy, [16] Cawood [17] and Maloney [18] have previously advocated delays from injury to surgery of no more than 24, 48, and 72 hours, respectively. In 2005, a retrospective chart review done by Biller et al., [19] patients were divided into two groups: Those repaired in 3 days or less and those repaired after 3 days. Another study, by Zachariades et al., [20] delineated delay as more than 14 days.

In our study, we considered late treatment to be after 72 hours based on the fact that outcome of fracture treatment is entirely dependent upon the cellular activity in the trauma region", and that the cellular response is at a maximum after 3-4 days. [18] and also supported by the information referred to by the Committee on Control of Surgical Infections of the Pre-and Post-operative Care Committee of the American College of Surgeons is that mandibular fractures that are delayed in receiving treatment can be classified as infected wounds [21].

In the present study, although we had 132 patients treated after 3 days; $80 \%$ of them actually were done within the $2^{\text {nd }}$ and 3 rd weeks post trauma (mean time to repair was 17.8 days); we still had 
a low infection rate $(5 \%)$ owing to the proper use of antibiotic prophylaxis which became an integral part of the standard treatment of mandibular fractures treated by open reduction and internal fixation. This correlated with other studies that found lower infection rates of between $5.8 \%$ and $7 \%$ [22,23].

However, like other retrospective studies this retrospective analysis may lead to information bias. Further research must be done into the proper timing associated with multi-variables as number of fractures and co-morbidities will benefit in the proper evaluation of this issue.

\section{Conclusion:}

The results presented here go with other studies and the analysis of this report provides important data for improving the treatment of the fractured mandible.

\section{REFERENCES}

1- Punjabi A.B. and Thaller S.R.: Late complications of mandibuar fracture. Operative Techniques in Plastic and Reconstructive Surgery, 5 (3): 266-74, 1998.

2- Mabrouk A.R., Helal H.A., Abdel Aal A.S. and Mahmoud N.A.: Incidence, Etiology and Patterns of Maxillofacial fractures in Ain-Shams University, Cairo, Egypt: A 4 Years Retrospective Study. Cranial Maxillofac Trauma Reconstruction, 07 (03): 224-32, 2014.

3- Zweig B.E.: Complications of Mandibular Fractures. Atlas Oral Maxillofacial. Surg. Clin. N. Am., 17: 93-101, 2009.

4- Abdelfadil E., Salem A.S., Mourad S.I. and Al-Belasy F.A.: Infected Mandibular Fractures: Risk Factors and Management. Oral Hyg. Health, 1: 102, 2013.

5- Stacey D.H., Doyle J.F., Mount D.L., Snyder M.C. and Gutowski K.A.: Management of mandible fractures. Plast. Reconstr. Surg., 117: 48e-60e, 2006.

6- Czerwinski M., Parker W., Correa J.A. and Williams H.B.: Effect of treatment delay on mandibular fracture infection rate. Plast. Reconstr. Surg., 122: 881, 2008.

7- Moreno J.C., Fernández A., Ortiz J.A. and Montalvo J.J.: Complication rates associated with different treatments for mandibular fractures. J. Oral Maxillofac. Surg., 58: 273-80, 2000.

8- Malanchuk V.O. and Kopchak A.V.: Risk factors for development of infection in patients with mandibular fractures located in the tooth-bearing area. J. Craniomaxillofac. Surg., 35: 57, 2007.

9- Webb L.S., Makhijani S., Khanna M., Burstein M.J., Falk A.N., et al.: A comparison of outcomes between immediate and delayed repair of mandibular fractures. Can. J. Plast. Surg., Winter, 17 (4): 124-6, 2009.
10- Anderson T. and Alpert B.: Experience with rigid fixation of mandibular fractures and immediate function. J. Oral Maxillofac. Surg., 50: 555-60; discussion 560-1, 1992.

11- Koury M.E.: Complications in the treatment of mandibular fractures, in Kaban LB, Pogrell AH, Perrot D: Complications in Oral and Maxillofacial Surgery. Philadelphia, PA, Saunders, pp 121-46, 1997.

12- Lucca M., Shastri K., McKenzie W., Kraus J., Finkelman M., et al.: Comparison of treatment outcomes associated with early versus late treatment of mandible fractures: A retrospective chart review and analysis. J. Oral Maxillofac. Surg., 68: 2484-8, 210.

13- De Matos F.P., Arnez M.F., Sverzut C.E. and Trivellato A.E.: A retrospective study of mandibular fracture in a 40-month period. Int. J. Oral Maxillofac. Surg., 39: 105,2010 .

14- Barker D.A., Oo K.K., Allak A. and Park S.S.: Timing for repair of mandible fractures. Laryngoscope, 121: 11603, 2011.

15- Hurrell M.J. and Batstone M.D.: The effect of treatment timing on the management of facial fractures: A systematic review. Int. J. Oral Maxillofac. Surg., Aug., 43 (8): 944$50,2014$.

16- Champy M., Lodde J.P., Schmitt R., Jaeger J.H. and Muster D.: Mandibular osteosynthesis by miniature screwed plates via a buccal approach. J. Maxillofac. Surg., 6: 14-21, 1978.

17- Cawood J.I.: Small plate osteosynthesis of mandibular fractures. Br. J. Oral Maxillofac. Surg., 23: 77-91. 3, 1985.

18- Maloney P.L., Lincoln R.E. and Coyne C.P.: A protocol for the management of compound mandibular fractures based on the time from injury to treatment. J. Oral Maxillofac. Surg., 59: 879-84. discussion 885-6, 2001.

19- Biller J.A., Pletcher S.D., Goldberg A.N. and Murr A.H.: Complications and the time to repair of mandible fractures. Laryngoscope, May, 115 (5): 769-72, 2005.

20- Zachariades N., Papavasilliou D., Papademe-Triou I., Koundouris I. and Rapidis A.: Neglected fractures of the facial bones. J. Maxillofac. Surg., 12: 36-40, 1984.

21- U.S. National Research Council of Medical Sciences, Ad Hoc Committee of the Committee of Trauma, Division of Medical Sciences, National Academy of SciencesNational Research Council: Postoperative wound infections: The influence of ultraviolet irradiation of the operating room and various other factors. Ann. Surg. 160: 1, (suppl 2), 1964.

22- Lamphier J., Ziccardi V., Ruvo A. and Janel M.: Complications of mandibular fractures in an urban teaching center. J. Oral Maxillofac. Surg., 61: 745-50, 2003.

23- Dhariwal D.K., Gibbons A.J., Murphy M., Llewelyn J. and Gregory M.C.: A two year review of the treatment and complications of mandibular angle fractures. J. R. Army Med. Corps., 148: 115-7, 2002. 